\title{
In between cultures: Social research in the intercultural context
}

\author{
Martin Weichbold
}

(C) Springer Fachmedien Wiesbaden 2015

From the very inception of sociology, cultural comparison has been a central tenet of both theoretical development and empirical research. In his book The Rules of Sociological Method (1895), Émile Durkheim claimed that intercultural comparison was the quintessential method for sociology. Likewise Max Weber, another of the field's founding fathers, conducted extensive studies showing the influence of culture (and especially religion) on the economic development of various societies. Although the topic has been raised by other prominent theorists, it somehow lost significance in sociology over the years, although it never completely left the scope of the field.

In recent decades, international and transnational questions have regained importance. The reasons are manifold and both endemic and external to the social sciences. The dynamics of globalisation have led to more and more intensive contacts between societies caused by economic, cultural or touristic exchange. Technological developments, especially the implementation and rise of the internet and political efforts such as European integration, have also been a result of and an impetus for further integration.

Along with these developments, the need for cross-national information has increased. With the founding of Eurostat, the countries of the European Community (now the European Union) began to harmonise their official statistics in order to establish a mutually comparable basis for political and economic decisions. Meanwhile, surveys started to become an important source of data. The first cross-national survey programme based on population samples was 'How Nations see Each Other', funded by UNESCO and conducted by William Buchanan and Hadley Cantril in six European countries, the United States, Mexico, and Australia in 1948-1949

M. Weichbold ( $\bowtie)$

FB Politikwissenschaft und Soziologie, Abteilung Soziologie und Kulturwissenschaft, Universität Salzburg,

Rudolfskai 42,

5020 Salzburg, Österreich

e-mail: martin.weichbold@sbg.ac.at 
(Buchanan and Cantril 1953). The oldest ongoing programme is the Eurobarometer, which started in the early 1970s by order of the European Commission and covers EU member states and selected additional countries. ${ }^{1}$ Today dozens of large international survey programs collect data from tens of thousands of respondents all around the world. ${ }^{2}$ In this regard, intercultural research is a success.

Taking a survey is complex by itself, but extending it across countries makes the endeavour even more complicated and expensive. The most obvious tasks this entails are translating the questionnaire and organising the fieldwork, but there are many other points to be considered. Over the years, extensive expertise has been gathered refining a specific methodology for cross-cultural surveys. A comprehensive overview of different considerations can be found in the 'Guidelines for Best Practice in Cross-Cultural Surveys' (Survey Research Center 2010), the outcome of an initiative by scholars active in cross-national or cross-cultural survey research. To supplement these guidelines and develop a more rigorous theoretical basis, some colleagues and I have devised a general framework for intercultural surveys (Bachleitner et al. 2014). One lesson we (and of course many other scholars) have learned is that methodical questions have multiple possible answers and each decision's various consequences must be considered carefully.

Cross-cultural comparison pertains not only to official statistics and surveys, but also to qualitative research. About a century ago, scholars at the Chicago School of Sociology started a tradition of research on the relations between different ethnic and cultural groups. 'The Polish Peasant in Europe and America: Monograph of an Immigrant Group', conducted by William I. Thomas and Florian Znaniecki and edited between 1918 and 1920, is one of the most famous studies of that period. Today sociology of migration and integration is again one of the most important fields for cross-cultural qualitative research, but of course there are many other subdisciplines in which social research is carried out beyond or across cultural borders.

Despite the diversity of methodological underpinnings, some general questions are universal. How can we obtain valid and comparable information when surveying people from different nations, ethnic groups or cultural backgrounds? Further, how can we compare these different cultures in empirical social research? The conclusions regarding survey research also hold true for qualitative studies: there is no silver bullet. Many steps must be taken in the course of the research process, and each researcher must carefully weigh the pros and cons of the research design and all decisions during the research process.

The methodical challenges of cross-cultural research (whether qualitative or quantitative in methodology) was the topic of a conference organised in Salzburg in October 2014 by the methodological section of the Austrian Society of Sociology. Selected participants were invited to expand upon their presentations for this issue of the Austrian Journal of Sociology (known in German as the Österreichische Zeitschrift für Soziologie).

\footnotetext{
${ }^{1}$ See http://ec.europa.eu/public_opinion/index_en.htm.

${ }^{2}$ For an overview of comparative studies worldwide, see http://www.gesis.org/das-institut/kompetenzzentren/fdz-internationale-umfrageprogramme/overview-of-comparative-surveys-worldwide/.
} 
The articles in the first section deal with quantitative research. Andreas Schmitz, Raphael H. Heiberger and Jörg Blasius seek a frame of reference for comparative survey research. Using an integrated data set from 181 countries and interpreting various variables in the sense of the habitus field theory, they show that the global field of power can be described by two dimensions: meta-capital and internal functionality, a very useful distinction for cross-cultural comparison. Alexander Seymer reflects upon the empirical implementation of class concepts in cross-national research and asks whether these concepts fulfil the requirements of equivalence if compared across countries. He shows that occupation-based concepts are better if carefully elaborated. Tuulij-Marie Kleiner wonders how cultural distance is affected by geographical proximity and national borders. Analysing Austrian regions (nuts2) by using the 2002-2008 European Social Survey, the article finds cultural spill-over effects between sub-national regions. While the national border clearly does affect cultural diversity between regions, neighbouring sub-national regions are culturally more similar to each other than distant ones.

In the second section we turn to qualitative research. Johannes Kloha and Sevgi Söyla draw our attention to the fact that migration studies often takes ethnic categories to be self-evident, although different ways of interpretation might be possible. They plead for researchers to reflect more critically on their assumptions and their own positions in order to avoid incorrect or undifferentiated conclusions. Yvonne Berger describes the subjectivity of researchers in intercultural research contexts focusing on the case of the People's Republic of China. Reporting her own research experiences, she shows how research situations are framed by distinctive practices and interactive identity work.

Finally, Jochen Gläser, Jana Bielick, Robert Jungmann, Grit Laudel, Eric Lettkemann, Grit Petschick and Ulla Tschida take another standpoint. Why should we always think of countries and nations when discussing cultural differences? They argue that the concept of cultural difference also applies to the sciences and ask how research cultures can be taken as an explanatory factor in sociology of science.

Acknowledgements I would like to thank all participants of the Salzburg conference for their presentations and discussions, the authors of this issue of ÖZS for their work, the reviewers for their helpful remarks and all the many others who were involved in preparing this issue.

\section{References}

Bachleitner, Reinhard, Martin Weichbold, Wolfgang Aschauer, and Markus Pausch. 2014. Methodik und Methodologie interkultureller Umfrageforschung. Zur Mehrdimensionalität der funktionellen Äquivalenz. Wiesbaden: Springer VS.

Buchanan, William, and Hadley Cantril. 1953. How nations see each other: A study in public opinion. Urbana: University of Illinois Press.

Durkheim, Ėmile. 1962 [1895]. The rules of sociological method. Trans. by Sarah A. Solovay, ed. by George E. G. Catlin. Glencoe: Free Press.

Survey Research Center. 2010. Guidelines for best practice in cross-cultural surveys. Ann Arbor, MI: Survey research center, Institute for social research, University of Michigan. Retrieved 06 (22): 2015. http://www.ccsg.isr.umich.edu/. 
Thomas, William I., and Florian Znaniecky. 1984 [1910-1920]. The polish peasant in Europe and America: Monograph of an immigrant group. Urbana: University of Illinois Press.

Weber, Max. 2003 [1905]. The Protestant Ethic and the Spirit of Capitalism. Mineola, NY: Dover Publications.

Martin Weichbold is Associated Professor for sociology and empirical social research at the Department of Political Science and Sociology at the University of Salzburg. His research interests are methodological questions, especially the construction of data used in the social sciences. 